\title{
Synthesis of Peracetic Acid and Determination
}

\author{
Ao Deng Ge Ri Le \\ Chemistry and Environment Science College of Inner Mongolia Normal University, \\ Inner Mongolia Hohhot 010022, China \\ e-mail: aodeng@imnu.edu.cn
}

\begin{abstract}
The preparation of peroxyacetic acid (PAA) using acetic acid and hydrogen peroxide $\left(\mathrm{H}_{2} \mathrm{O}_{2}\right)$ in the presence of perfluorinated resinsufonic acid (Nafion-H) in room temperature has been studied. The prepared PAA is determinate with Au electrode by cyclic voltammograms of after background subtraction. A form reaction of PAA is reach equilibrium at reaction time was around 6 hours. The concentration of PAA solution prepared was increased with the reaction time and longer reaction time it was almost constant (ca. $4.0 \mathrm{mmol} / \mathrm{L}$ ).
\end{abstract}

Key words-Peroxyacetic Acid; Synthesis; Nafion - H; Determination

\section{I . INTRODUCTION}

In recent years, peracetic acid (PAA) has been widely used as a disinfectant in the food and as a bleaching agent for textile and paper [1-3]. Preparation of PAA is generally based on a reversible chemical reaction between hydrogen peroxide $\left(\mathrm{H}_{2} \mathrm{O}_{2}\right)$ and lower aliphatic carboxylic acid (eq.1) under the catalysis of a strong acid, e.g., sulfuric acid. The reaction proceed with a rate constant dependent of the concentration of catalytic acid and temperature [4].

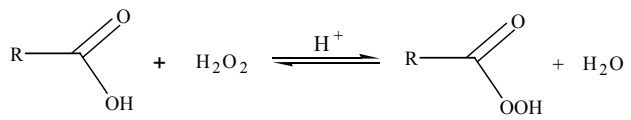

However, this technique suffers from the drawbacks such as separation of soluble catalyst from the reaction mixture and corrosion of the reactor. Solid superacids have been used effectively in various acid-catalyzed reactions in place of the conventional acid catalysts because of their higher catalytic activity, minimal corrosion problems, ease of separation and reusability [5, 6]. Now we wish to report the preparation of PAA using acetic acid and $\mathrm{H}_{2} \mathrm{O}_{2}$ in presence of the solid superacid, Nafion-H (a solid perfluorinated resinsulfonic acid) in room temperature. For the first time, the prepared PAA is determinate with gold electrode by cyclic voltammograms of after background subtraction.

\section{II . EXPERIMENTAL}

A. Preparation of PAA. Quantitative $31 \% \mathrm{H}_{2} \mathrm{O}_{2}$ and Nafion resins add to $1 \mathrm{~mol} / \mathrm{L}$ acetic acid solution. Agitate by stir in room temperature. All solutions were prepared using deionized water.

$B$. Determination of PAA. The Au working electrodes were polished with emery paper and aqueous slurries of finer aluminium power $(1 \mu \mathrm{m}$ and $0.06 \mu \mathrm{m})$ successively. Then they were sonicated in water for $5 \mathrm{~min}$, and electropolished in $0.05 \mathrm{~mol} / \mathrm{L} \mathrm{H}_{2} \mathrm{SO}_{4}$ solution for about 10 min before the typical cyclic voltammogram was taken. The platinum wire and $\mathrm{NaCl}$-saturated $\mathrm{Ag} / \mathrm{AgCl}$ electrode were used as counter and reference electrode (Figure 1).

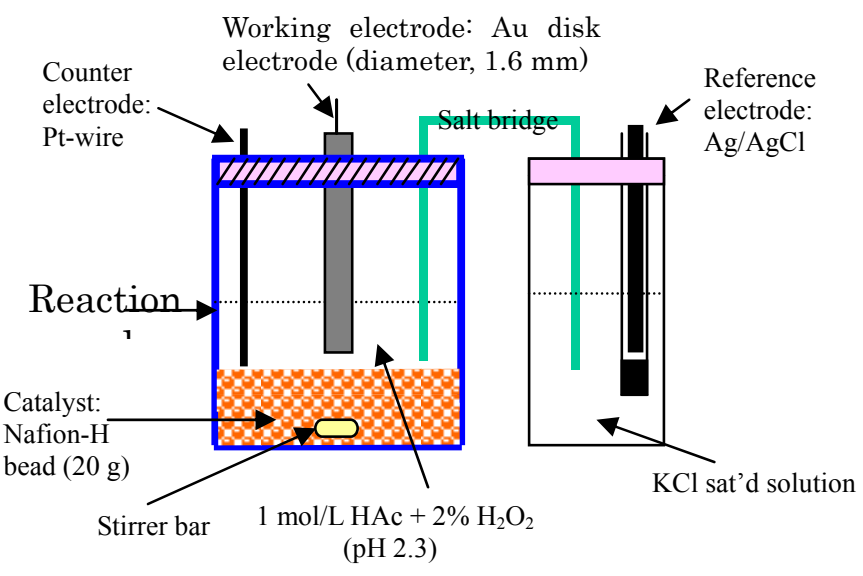

Figure 1 Reaction Scheme for PAA Synthesis.

C. Regeneration of Nafion-H Catalyst. Treated in boiling deionized water for $2 \mathrm{~h}$ and then filtered. The resin is then stirred in $20 \% \mathrm{HNO}_{3}$ for $4-5 \mathrm{~h}$ at room temperature and filtered. This acid treatment is repeated three to four times to obtain maximum exchange of potassium ion with protons in the polymer. The resin is finally washed several times with water until a neutral filtrate is obtained followed by drying under vacuum at $\sim 105^{\circ} \mathrm{C}$ for at least $24 \mathrm{~h}$.

\section{RESULTS AND DISCUSSION}

Figure. 2 shows cyclic voltammetric behaviors of PAA and $\mathrm{H}_{2} \mathrm{O}_{2}$ obtained at $\mathrm{Au}$ electrode in $\mathrm{N}_{2}$-saturated $1 \mathrm{~mol} / \mathrm{L}$ acetic acid solution. We can see two well-separated reduction peaks or the reduction of PAA and $\mathrm{H}_{2} \mathrm{O}_{2}$, respectively. This can be easily noticed from the increase in the intensity of the two peaks with the increase in the concentration of PAA and $\mathrm{H}_{2} \mathrm{O}_{2}$ (curves b, c, and d), from the increase in the peak intensity only at $-0.4 \mathrm{~V}$ on keeping the concentration of PAA constant, while increasing that of $\mathrm{H}_{2} \mathrm{O}_{2}$ (curves $d$, e, and $\mathrm{f}$ ). It follows from what has been said that PAA can be examined in acetic acid 
solution. The question, which we must consider, next is influence of oxygen.

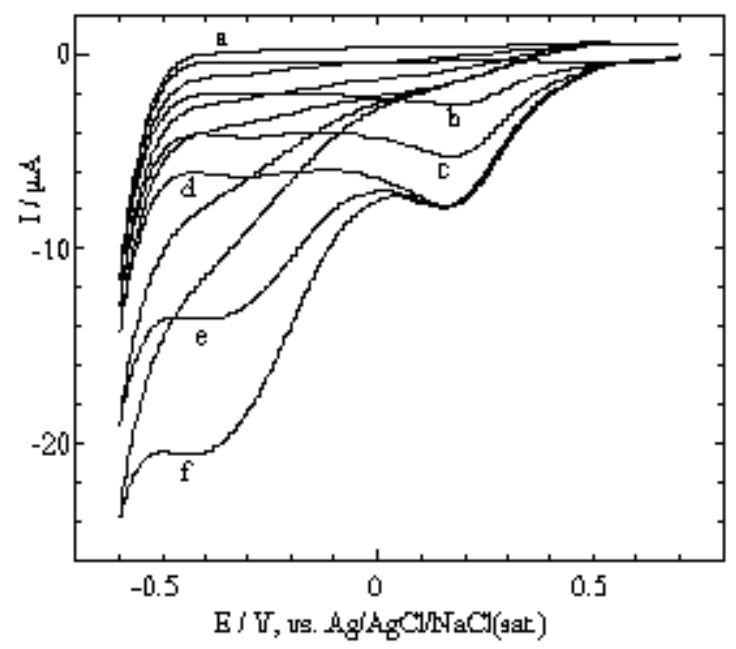

Figure 2 Cyclic voltammograms obtained for the PAA and $\mathrm{H}_{2} \mathrm{O}_{2}$ at $\mathrm{Au}$ electrode $(\phi=1.6 \mathrm{~mm})$ in $\mathrm{N}_{2}$-saturated $1 \mathrm{~mol} / \mathrm{L} \mathrm{CH}_{3} \mathrm{COOH}$ solution $(\mathrm{pH}$ $=2.3$ ). Potential scan rate: $100 \mathrm{mV} / \mathrm{s}$. (a) blank.

(b) $0.275 \mathrm{mmol} / \mathrm{L} \mathrm{PAA}+0.092 \mathrm{mmol} / \mathrm{L} \mathrm{H}_{2} \mathrm{O}_{2}$.

(c) $0.55 \mathrm{mmol} / \mathrm{L} \mathrm{PAA}+0.184 \mathrm{mmol} / \mathrm{L} \mathrm{H}_{2} \mathrm{O}_{2}$.

(d) $0.825 \mathrm{mmol} / \mathrm{L} \quad \mathrm{PAA}+0.276 \mathrm{mmol} / \mathrm{L} \quad \mathrm{H}_{2} \mathrm{O}_{2}$.

(e) $0.825 \mathrm{mmol} / \mathrm{L} \quad \mathrm{PAA}+0.776 \quad \mathrm{mmol} / \mathrm{L} \quad \mathrm{H}_{2} \mathrm{O}_{2}$.

(f) $0.825 \mathrm{mmol} / \mathrm{L} \mathrm{PAA}+1.276 \mathrm{mmol} / \mathrm{L} \mathrm{H}_{2} \mathrm{O}_{2}$.

Figure. 3 shows cyclic voltammograms of PAA reduction at $\mathrm{Au}$ electrode in acetic acid solutions under $\mathrm{N}_{2}$ and air. Oxygen reduction $(-0.1 \mathrm{~V})$ between PAA and $\mathrm{H}_{2} \mathrm{O}_{2}$ reduction, no affect for determine of PAA. So far, we have seen how determine of PAA in acetic acid solutions, oxygen was no affect for examine of PAA.

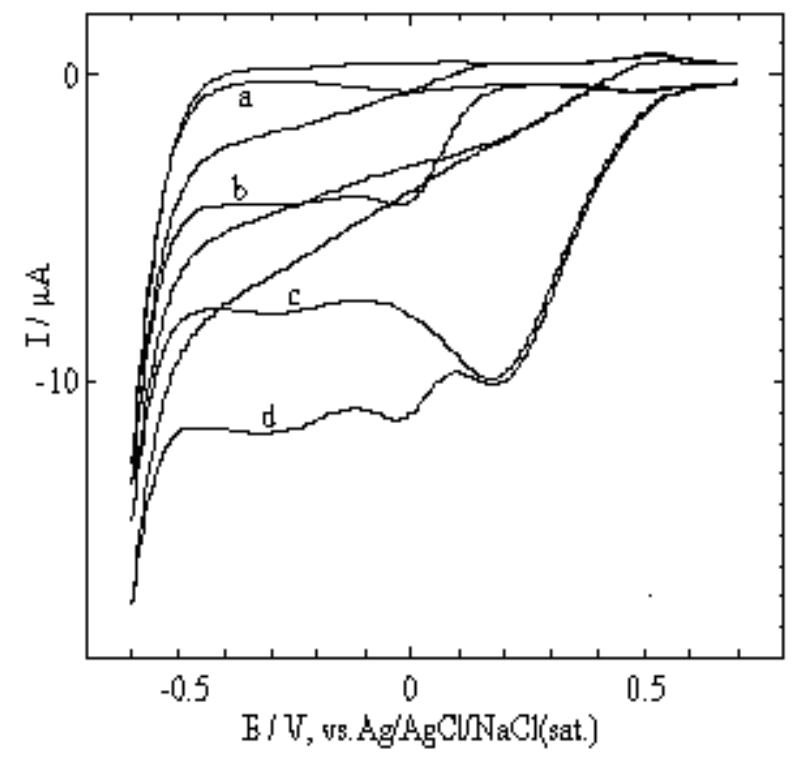

Figure 3 Cyclic voltammograms obtained at $\mathrm{Au}$ electrode $(\phi=1.6 \mathrm{~mm})$ in $(\mathrm{a}, \mathrm{c}) \mathrm{N}_{2}$ and $(\mathrm{b}, \mathrm{d})$ air-saturated $1 \mathrm{~mol} / \mathrm{L} \mathrm{CH}_{3} \mathrm{COOH}$ solutions $(\mathrm{pH}=$ $2.3)$ in the absence $(\mathrm{a}, \mathrm{b})$ and presence $(\mathrm{c}, \mathrm{d})$ of $2.2 \mathrm{mmol} / \mathrm{L}$ PAA + $0.73 \mathrm{mmol} / \mathrm{L} \mathrm{H}_{2} \mathrm{O}_{2}$
Figure. 4 show Cyclic voltammograms obtained at $\mathrm{Au}$ electrode in $\mathrm{N}_{2}$-saturated $1 \mathrm{~mol} / \mathrm{L} \mathrm{CH}_{3} \mathrm{COOH}$ solution containing $2 \% \mathrm{H}_{2} \mathrm{O}_{2}$. Solid and dotted lines show CVs obtained in the absence and presence of $4.4 \mathrm{mmol} / \mathrm{L} \mathrm{PAA}$, respectively. $\mathrm{CV}$ for the reduction of $\mathrm{PAA}$, which was corrected by subtracting solid line $\mathrm{CV}$ from dotted line $\mathrm{CV}$ (Figure.4 inset). The concentration of PAA can be obtained, according to the standard curve of concentration of PAA to current intensity.

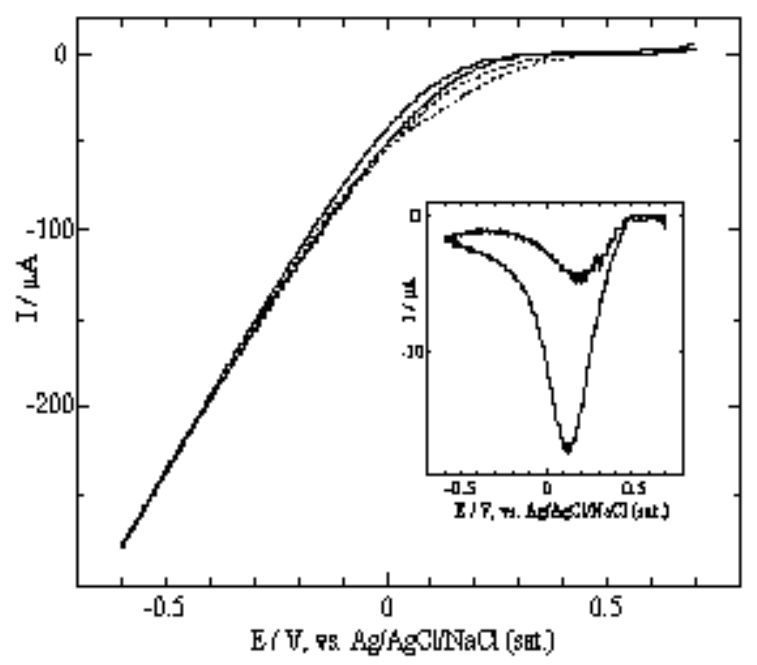

Figure 4. Cyclic voltammograms obtained at $\mathrm{Au}$ electrode in $\mathrm{N}_{2}$-saturated $1 \mathrm{~mol} / \mathrm{L} \mathrm{CH} \mathrm{CH}_{3} \mathrm{COOH}$ solution containing $2 \% \mathrm{H}_{2} \mathrm{O}_{2}$. Solid and dotted lines show CVs obtained in the absence and presence of 4.4 $\mathrm{mmol} / \mathrm{L}$ PAA, respectively. Inset: $\mathrm{CV}$ for the reduction of PAA, which was corrected by subtracting solid line $\mathrm{CV}$ from dotted line $\mathrm{CV}$. Potential scan rate: $100 \mathrm{mV} / \mathrm{s}$.

Figure. 5 show the concentration of PAA produced by the $1 \mathrm{~mol} / \mathrm{L}$ acetic acid solution $(20 \mathrm{~mL})$ containing $2 \%$ $\mathrm{H}_{2} \mathrm{O}_{2}$ and Nafion- $\mathrm{H}$ (about $20 \mathrm{~g}$ ) in batch- wise operation as a function of the reaction time. The concentration of PAA solution prepared was increased with the reaction time and longer reaction time it was almost constant (ca. $4.0 \mathrm{mmol} / \mathrm{L}$ ). A form reaction of PAA is reach equilibrium at reaction time was around 6 hours. PAA can not be obtained, in test time, without Nafion. In conclusion, we have succeeded in preparing PAA from acetic acid and hydrogen peroxide using solid superacid catalysts Nafion-H. 


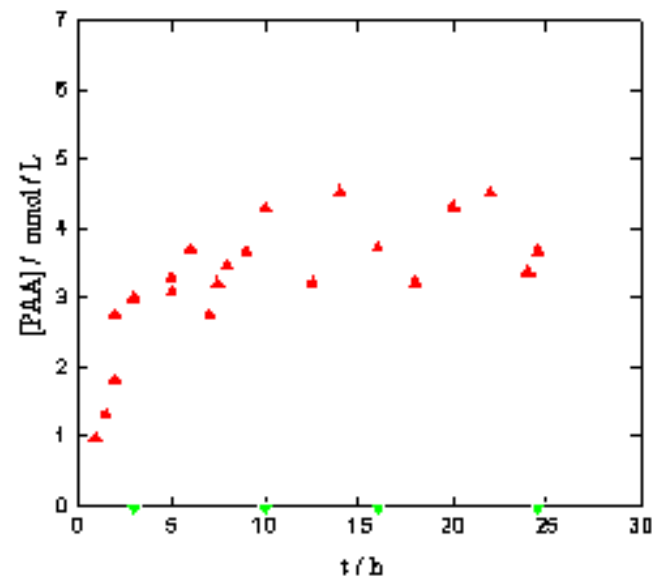

Figure 5. Plot of PAA concentration vs. reaction time. ( $\mathbf{\Delta}$ ) presence of Nafion bead, and $(\boldsymbol{\nabla})$ absence of Nafion bead.

\section{REFERENCE}

[1] Pinkernell, U.; Karst, U.; Cammann, K. Determination of Peroxyacetic Acid Using High-Performance Liquid Chromatography with External Calibration. Anal. Chem. 1994, 66, 2599-2602

[2] New York CINCINATI ATLANTA DALLAS SAN FRANCISO, LON DON TORONTO MELBOURNE, The condensed chemical dictionary. p452, p660

[3] Yuan, Z.; Ni, Y.; van Heiningen, A.R.P. Kinetics of Peracetic Acid Decomposition Part 1: Spontaneous Decomposition at Typical Pulp Bleaching Conditions. Can. J. Chem. Eng. 1997, 75, 37-41

[4] Cheremisinoff, N. P. Handbook of Hazardous Chemical Properties; Butter-Worth-Heinemann: Woburn, MA, 2000

[5] T. Yamato, C. Hideshima, G. K. SuryaPrakash, George A. Olah, Solid Superacid Catalyzed Organic Synthesis. Perfluorinated Resinsufonic Acid (Nafion-H) Catalyzed Ring Closure Reaction of 2, 2'-Dihydroxybiphenyls. A Preparative Route to Dibenzofurans. J. Org. Chem. 1991, 56, 3192-3194

[6] Yuan, Z.; Ni, Y.; van Heiningen, A.R.P. Kinetics of the Peracetic Acid Decomposition Part 2: pH Effect and alkaline Hydrolysis. Can. J. Chem. Eng. 1997, 75, 42-47 